\title{
19
}

\section{Study of Decomposition of Grass and Leaves}

\author{
Justin Strynchuk, John Royal and Gordon England
}

A significant source of nutrient input to water bodies is from grass clippings and leaves (yard debris) washed into drainage systems during storms. Brevard County, Florida, Surface Water Improvement Department conducted a study to determine the nutrient release rates from grass clippings and leaves in order to better understand the chemistry and resultant pollutant loading mechanisms.

Sixty-gram samples of mixed freshly cut St. Augustine yard grass (Stenolaphrum secundalum) and oak leaves (Quercus sp.) were placed into opaque containers. Coarsely filtered storm/ditch water was added to fill the containers to the 8-liter marks. Samples were allowed to go anaerobic, typical of wet sump best management practice (BMP) structure conditions, and tested periodically after soaking and processing. At intervals of: $0,1,5,9,14,22,34$, $50,70,130$, and 180 days, triplicate bucket sets were agitated to simulate mixing from stormwater influx, then poured through a Number 35, US Standard Soil Sieve, and the liquid analyzed. The solids that remained in or on the sieve were analyzed, and the results compared to those of the corresponding liquid phase.

The results represent the lawn and leaf litter decomposition and nutrient release rates found in east Florida. This information may be useful in the selection or site design of BMPs for treating nutrients in stormwater, and determining cleaning frequency.

\subsection{Introduction}

Sediment carried by stormwater may reduce the ability of light to penetrate water, thereby hindering the growth of marine plants. Sediment may also cover and smother the aquatic plants, resulting in die-off. It is hypothesized that

Strynchuk, J., J.C. Royal and G.B. England. 2003. "Study of Decomposition of Grass and Leaves." Journal of Water Management Modeling R215-19. doi: 10.14796/JWMM.R215-19.

(C) CHI 2003 www.chijournal.org ISSN: 2292-6062 (Formerly in Practical Modeling of Urban Water Systems. ISBN: 0-9683681-7-4) 
leaves, grass clippings and organic matter from yards increase oxygen demands and may contribute nutrients to algae blooms that can result in fish kills. Brevard County has taken a pro-active stance to reduce sediment and nutrient contributions whenever possible through retrofitting areas that currently have little or no stormwater treatment provided. Several treatment methods currently utilized by the County include baffle boxes and stormwater inlet traps that retain these materials before they enter surface waters. This experiment was undertaken to explore the fate of nutrients in the form of grass and leaves, which are washed into waterbodies or wet BMP sumps.

Baffle boxes often receive constant groundwater flows and retain standing water in the chambers where the sediment and debris are collected. The question has been posed whether organic constituents may leach out of the collected materials only to be carried to surface waters during the next storm event or by background flows. A significant source of nutrient input to water bodies is from grass clippings and leaves washed into drainage systems during storms. Brevard County Surface Water Improvement conducted this study to determine the nutrient release rates from grass clippings and leaves in order to better understand the chemistry and resultant pollutant loading mechanisms. The goal of this experiment was to identify variations in the concentrations of constituents, with an ultimate goal of determining a timetable for cleanout of applicable BMP structures to prevent the release of targeted pollutants.

\subsection{Materials and Methods}

Brevard County has installed over 35 baffle boxes over the last $10 \mathrm{y}$ as part of their ongoing stormwater retrofit program to reduce pollutants entering the Indian River Lagoon. As a result of visual inspections and records of over 700 baffle box clean outs, it was determined that the organic yard waste they collect is typically a mixture of grass clippings and leaf litter. Therefore this study was conducted on grass clippings collected from a yard containing oak trees, and included between $31 \%$ to $66 \%$ oak leaf litter by weight. This yard had never been fertilized or serviced by a sprinkler system.

Water was collected from two storm water conveyance canals. Cleaned opaque sample buckets and lids were rinsed with the filtered water prior to final filling with $8 \mathrm{~L}$ of 180 micron (sieve opening or pore size) filtered water. Previously refrigerated, week old, 60-g samples of mixed St. Augustine yard grass (Stenolaphrum secundalum) and oak leaves (Quercus sp.) were placed into the containers, and mixed to wet the grass. This was to simulate rainfall 
washing grass clippings into a retaining BMP sump. The tops of the buckets were loosely fit to allow off-gassing but minimize evaporation. The buckets were allowed to remain undisturbed in a non-climate-controlled storage area; subjected to indirect light, and temperature swings between 25 and $37^{\circ} \mathrm{C}$. Samples were allowed to go anaerobic, typical of wet sump BMP structure conditions, and tested periodically after the soaking and processing described below.

Six replicate samples of the raw grass and oak leaves were dried to constant weight in a desiccator. The samples averaged a loss of approximately $54 \%$ of their weight after the first day of desiccation. The average dried weight of these initial samples was $28 \mathrm{~g}$, with virtually all of the grass being retained on a U.S. Standard \#35 sieve. The numbers returned upon analysis for chemical and physical characteristics varied with each sample. This was expected due to variation within the small (triplicate) sample group; particularly when considering the physical characteristics of the grass blades, grass stems and nodes, oak leaves, and oak stems. Virtually all of the weight lost during desiccation was due to water loss from the grass, as the oak leaves had dried out prior to falling. Most of the water released by the oak leaves had been gained through compaction and mixing with the freshly cut grass in the lawn mower grass catch bag. Sample weights for the six initial samples used to determine representative yard grass-oak leaf ratios decreased during the hour it took to sort out individual grass and oak leave fragments to determine component ratios.

At intervals of: $0,1,5,9,14,22,34,50,70,130$, and 180 days, triplicate bucket sets were selected by blind lottery, agitated to simulate mixing from stormwater influx, then sent to the contract laboratory for processing. The sample was poured through a \#35, US Standard Soil Sieve. This sieve has a pore opening of 500 microns ( 0.0197 in). The solids that remained in or on the sieve were analyzed for weight at apparent external dryness, total kjeldahl nitrogen (TKN), biochemical oxygen demand at 5 days $\left(\mathrm{BOD}_{5}\right)$, and total phosphorous as $\mathrm{P}$ (TP as $\mathrm{P}$ ). The liquids that passed through the filter were analyzed for: color, $\mathrm{BOD}_{5}, \mathrm{TKN}$, and TP as P. A select group of constituent pollutants is discussed here; a more comprehensive list is discussed in the full report.

The residue (solid phase) was weighed, percentage moisture determined, then the residue analyzed. The mass of the mixed grass and oak leaves residue dropped from an average of $28 \mathrm{~g}$ to $16 \mathrm{~g}$ within the first $15 \mathrm{~d}$ of saturation, a loss of $43 \%$. The samples then stabilized at weights between $13 \mathrm{~g}$ and $20 \mathrm{~g}$ for the duration of the $180-\mathrm{d}$ sampling period. No attempt was made to differentiate between percent decomposition of grass to oak leaf ratios, but observations 
made on the mixture throughout the study revealed almost total solution of the grass, with little obvious physical decomposition evident of the oak leaves, even out to the $180 \mathrm{~d}$ mark.

In order to allow a more straightforward comparison of concentrations of constituents that leached into the water to the constituent concentrations remaining in the solids, $\mathrm{mg} / \mathrm{L}$ was correlated to the average dry weight of the grass that was placed in the container for leaching $(28 \mathrm{~g}$ grass $/ 8 \mathrm{~L}$ liquid $=3.5 \mathrm{~g}$ grass/L liquid). A ratio was then applied to determine the constituent level that would have leached from $1000 \mathrm{~g}(1 \mathrm{~kg})$ of dry solids. This allows direct comparison of $\mathrm{mg} / \mathrm{kg}$ solids concentration to $\mathrm{mg} / \mathrm{kg}$ leachate.

\subsection{Results}

The weight of the grass and oak leaf samples at initial weighing before immersion was approximately $60 \mathrm{~g}$. The initial dried weight of these initial samples averaged $28 \mathrm{~g}$, indicating initial moisture content of $58 \%$. By the end of day 1 , the moisture content of the wet samples increased to approximately $85 \%$, indicating that some absorption of water had taken place. Also after one day of immersion and subsequent drying, the grass and leaf mixtures weighed an average of $22 \mathrm{~g}$. By the end of $5 \mathrm{~d}$, the dried weight values averaged $18 \mathrm{~g}$, a total loss of $10 \mathrm{~g} \mathrm{(36 \% )}$ from the original average dry weight of $28 \mathrm{~g}$. No further change in the moisture content was discerned throughout the $180 \mathrm{~d}$ of the experiment. Even though the total weight of the solids reduced by $71 \%$ over the course of the study, the ratio of $85 \%$ moisture remained constant. These values, combined with laboratory observations, indicate that most of the residual components after day 5 may be relatively inert oak leaves. See Table 19.1 .

Initial values for TKN concentrations for the liquid phase raw mixed oak leaf and grass samples averaged $3.4 \mathrm{~g} / \mathrm{kg}$. After immersion for one day, the TKN concentrations rose $31 \%$, to $4.9 \mathrm{~g} / \mathrm{kg}$ (this corresponded to a loss of TKN from the solid phase of only $11 \%$ ). The total kjeldahl nitrogen concentrations of the liquid portion of each sample fell steadily from that point, to stabilize around 1.4 $\mathrm{g} / \mathrm{kg}$ by day 50 . Approximately $70 \%$ of the total loss of TKN from the liquid phase sample took place by the day 50 sample. At the day 180 sample, the liquid TKN concentrations exhibited a slight increase from the day 130 values. This may have been the result of eventual decomposition of the oak leaves, but the study was halted at day 180 and a definite trend past that point could not be substantiated. See Figure 19.1. 
Table 19.1 Grass and leaf breakdown.

\begin{tabular}{ccccc} 
Trial & $\begin{array}{c}\text { Raw Grass } \\
\text { mass (g) }\end{array}$ & $\begin{array}{c}\text { Raw Oak Leaf } \\
\text { mass (g) }\end{array}$ & $\begin{array}{c}\text { Percent Raw } \\
\text { Grass } \\
\text { by weight }\end{array}$ & $\begin{array}{c}\text { Raw Grass Clipping } \\
\% \text { by visual estimate }\end{array}$ \\
\hline 1 & 30.70 & 30.70 & $50 \%$ & $67 \%$ \\
2 & 31.20 & 25.00 & $56 \%$ & $48 \%$ \\
3 & 39.70 & 17.70 & $69 \%$ & $63 \%$ \\
4 & 35.89 & 17.24 & $68 \%$ & $63 \%$ \\
5 & 17.74 & 34.64 & $34 \%$ & $43 \%$ \\
6 & 22.43 & 24.73 & $48 \%$ & $52 \%$ \\
\hline
\end{tabular}

The concentrations depicted a quick leaching of the TKN fractions. The solid phase TKN concentrations began with an initial cut grass and leaf average value of $19.0 \mathrm{~g} / \mathrm{kg}$. This value dropped to $17.0 \mathrm{~g} / \mathrm{kg}$ after one day of immersion; a loss of $11 \%$ in a single day. After the second day, concentrations remained somewhat stable until after day 22 , whereupon they slowly began to rise. A correlating fluctuation was not observed in the liquid phase. The values for samples analyzed on day 34 averaged approximately $26.0 \mathrm{~g} / \mathrm{kg}$, an increase of some $28 \%$ over the day 22 values. The solid phase TKN values fell from their peak at day 34 to their lowest points during the study by the day 130 samples. Initially, this reduction corresponds to subsequent peaks in the nitrite and nitrate components of the liquid phase; and indicates that ammonia, or some other unmeasured nitrogen fraction, was being released into the water by the solid mass. Since a TKN analysis can include the ammonia, but not nitrite/nitrate fractions of nitrogen, it appears that this was a period of rapid decomposition of the nitrogenous compounds present in the mixed grass and oak leaves.

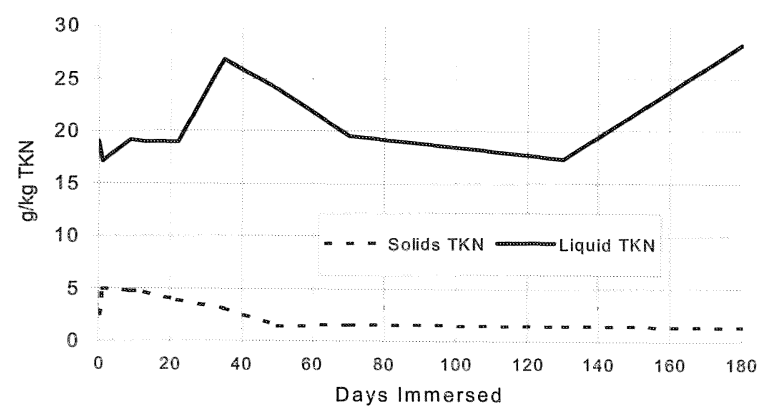

Figure 19.1 Mixed leaves and grass liquid and solids TKN. 
Perhaps the most dramatic illustration of the effects of leaching on mixed lawn grass and oak leaves was observed in the variations in total phosphorous as phosphorous (P) concentrations (see Figure 19.2). $1 \mathrm{~kg}$ of raw mixed grass and oak leaf solids yielded $1.9 \mathrm{~g}$ of total phosphorous as $\mathrm{P}$, prior to wetting. Analysis of the liquid phase for total phosphorous as $P$ revealed an average raw water composition of approximately $125 \mathrm{mg} / \mathrm{kg}$ of total phosphorous as $\mathrm{P}$. When the grass and leaves were added, there was an $89 \%$ increase in the liquid phase total phosphorous as $\mathrm{P}$ concentrations (to $1,057 \mathrm{mg} / \mathrm{kg}$ ) within the first day. By day 4, the values in the liquid phase had stabilized around $1,000 \mathrm{mg} / \mathrm{kg}$; remaining there for the course of the study.

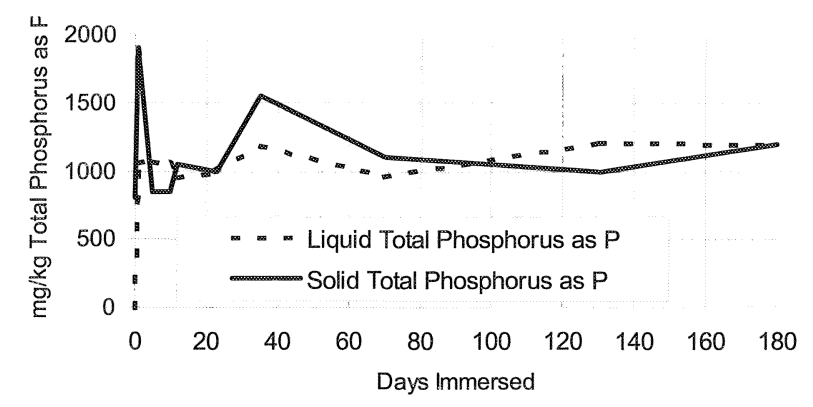

Figure 19.2 Mixed leaves and grass, liquid and solid total phosphorus as P.

The solid phase of the total phosphorous as $\mathrm{P}$ analysis depicted a very rapid leaching of phosphorous from an initial fresh grass and leaf value of $1,900 \mathrm{mg} /$ $\mathrm{kg}$; to a value of $880 \mathrm{mg} / \mathrm{kg}$ after the first day (a reduction of $54 \%$ ). There is evidence that this leached phosphorous made its way into the water column and increased the liquid phase total phosphorous as $\mathrm{P}$ concentrations significantly over the first day, and increased them slightly over the next $22 \mathrm{~d}$. Simply put, for the first week, when the solid phase phosphorous concentrations went down, the liquid phase values went up. However, after day 22 both the liquid and solid phase values and ratios between the respective values fluctuated. This may have been due to phosphorous changing state between solid and liquid phases.

$1 \mathrm{~kg}$ of raw mixed grass and oak leaf solids yielded $21.3 \mathrm{~g}$ of BOD, prior to wetting. The liquid phase $\mathrm{BOD}_{5}$ values immediately rose sharply $(700 \%)$ from an initial demand of approximately $4.5 \mathrm{~g} / \mathrm{kg}$ to peak at $40.0 \mathrm{~g} / \mathrm{kg}$ by day 
9. This corresponds to the peak in biological activity for the decomposition process. The demand then fell just as rapidly, to stabilize by day 22 at concentrations between 2.5 and $4.0 \mathrm{mg} / \mathrm{kg}$; which it maintained throughout the duration of the experiment. This can be thought of as the bloom and die-off phases of aerobic bacteria and other organisms present and active in the liquid phase. Basically, virtually all those nutrients readily available to aerobic organisms were used up within the first 22 days of the study. As the chemistry of the static containers moved from aerobic to anaerobic situations, there was a progression of biological and chemical reactions that occurred to take advantage of the conditions present.

The biochemical oxygen demand values for the solid fractions illustrated a progression from an initial value of $21.5 \mathrm{~g} / \mathrm{kg}$ for the raw grass, which fell $19 \%$ in the first day to $17.3 \mathrm{mg} / \mathrm{kg}$. By day 5 , the $\mathrm{BOD}_{5}$ values of the grass and oak leaf solids had fallen by a total of $25 \%$ from their initial concentrations. From day 5 on, the BOD values began to rise again, reaching a maximum value of 33.0 $\mathrm{g} / \mathrm{kg}$ by day 34 . This corresponds to the maximum decomposition rate of the solid phase grass and oak leaf components. By the time day 70 arrived, the samples were essentially biologically "dead," with a steady solid and liquid phase $\mathrm{BOD}_{5}$. Some minor biological activity was still taking place, but relatively little more biological breakdown could be expected under continuation of the existing environmental conditions. See Figure 19.3.

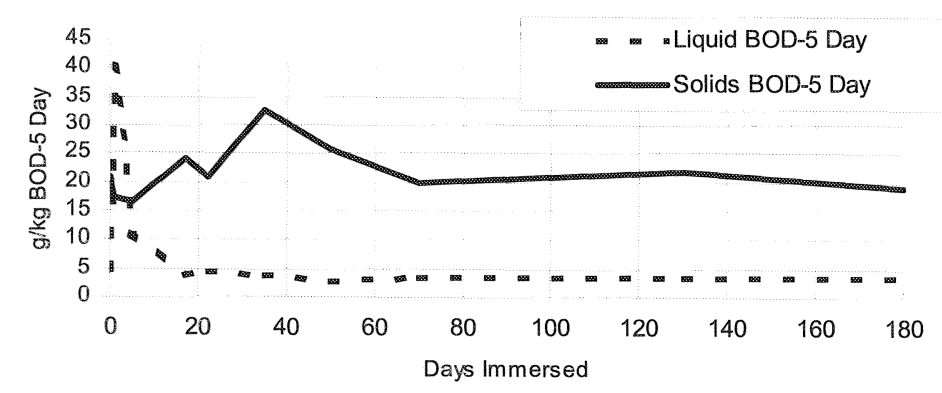

Figure 19.3 Mixed grass and leaves, liquid and solid $\mathrm{BOD}_{5}$.

The color of the water prior to mixing in the mixed leaves and grass was 140 PCU. After one day of soaking with the solids, the color then measured 193 PCU in the liquid phase, an increase of $38 \%$. By day 22, the color levels had stabilized at $350 \mathrm{PCU}$, an increase of $150 \%$ over the original background water. 
Color is coming under increasing scrutiny as one of the major attenuating agents of sunlight reaching seagrasses and other submerged aquatic plants. In conjunction, color is one of the most expensive pollutant components of surface water to remove. It would seem prudent that wet-detention/retention BMPs be cleaned as soon as possible after wash-down of yard debris entering the catch basin. There appears to be real value gained in doing so, up to 22 days after the grass and leaves being submerged. See Figure 19.4.

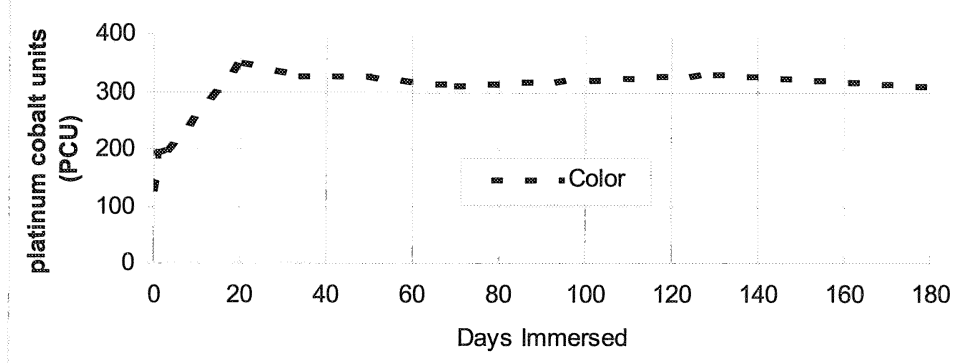

Figure 19.4 Mixed grass and leaves, liquid phase colour.

\subsection{Discussion and Conclusion}

The results of this study are presented in Figures 19.5 - 19.12. Most organicbased pollutants, which leach from grass clippings and leaves into water, will be released within 1 to $22 \mathrm{~d}$, depending on the pollutant. For example, the $\mathrm{BOD}_{5}$ concentrations peaked at $9 \mathrm{~d}$; color was continuously released between 1 and $22 \mathrm{~d}$; and most of the phosphorous was released within the first day of grass immersion. Based on these preliminary results it appears that in order to avoid significant leaching of most "pollutants", it is desirable to quickly remove organic debris from collection devices that retain water. It would be best to design yard debris trap basins which retain the solids in a dry area, rather than dealing with the engineering and economic hardships of removing these released pollutants from the stormwater stream. Even traditional wet detention ponds or wetlands would benefit from upstream, dry, inlet devices to reduce the pollutant loadings by removing them as solids, rather than dealing with the leachate in the liquid form in the ponds. 
Since particular pollutant concentrations peaked at different times, by matching the clean-out schedule to the pollutant it is conceivable one may be able to selectively remove a particular pollutant fraction. If these devices are not regularly cleaned quickly, and there is background flow or a storm event, one would have to conclude that a large percentage of the organic matter previously collected is being released and the component pollutants are actively flushed out to the surface waters.

In a prior grass monoculture screening study, significant gas production (hydrogen sulfide and methane) was evident after about $7 \mathrm{~d}$ of soaking. This fermentation was not observed in the current mixed grass and oak leaf study, possibly due to a different bacterial flora. The water source for the prior study was primarily groundwater flowing into a baffle box, whereas the water source

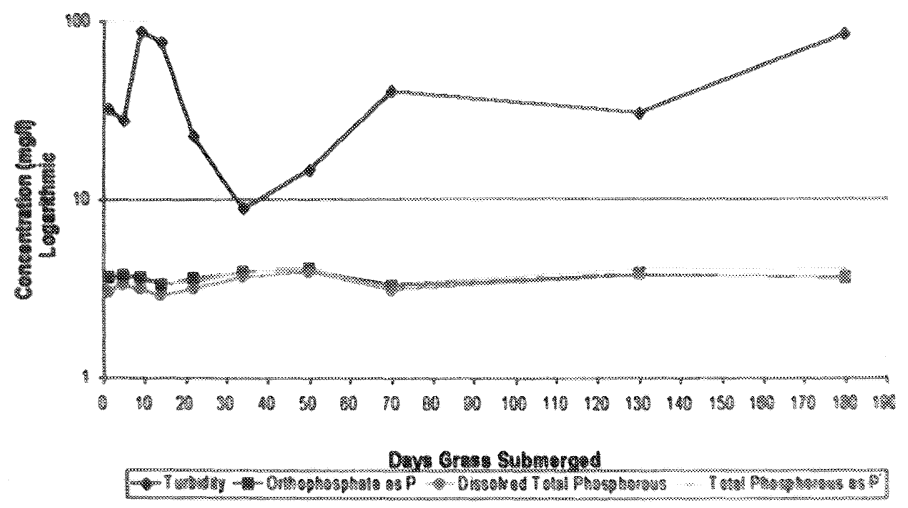

Figure 19.5 Mixed grass and leaves, turbidity vs phosphorus fractions.

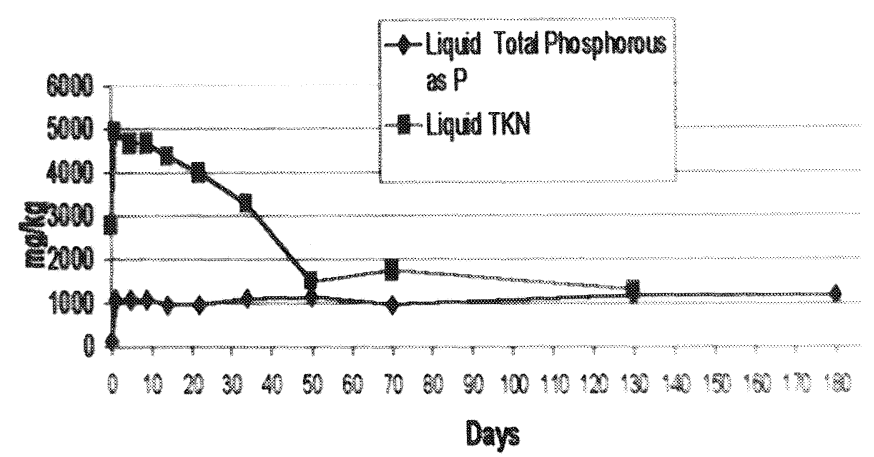

Figure 19.6 Mixed grass and leaves liquid phases TKN vs TP. 


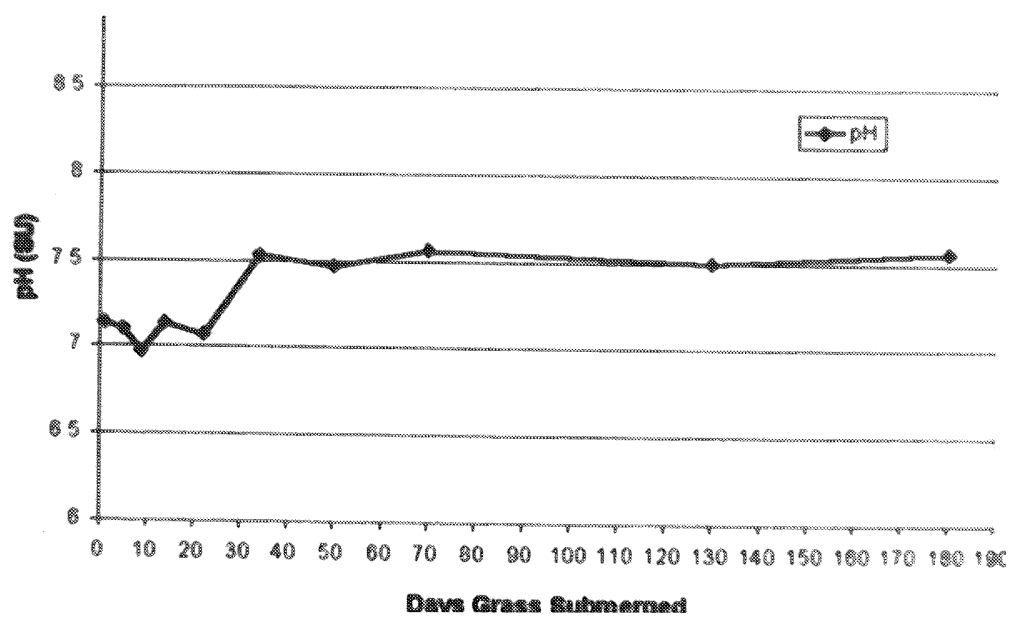

Figure 19.7 Mixed grass and leaves $\mathrm{pH}$.

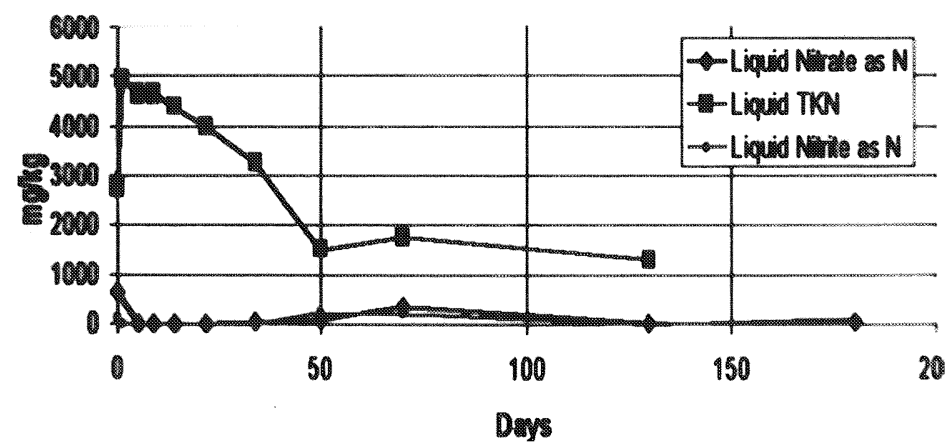

Figure 19.8 Mixed grass and leaves nitrogen fractions.

for the mixed grass and oak leaf study was surface and stormwater. It may be that the bacteria predominating in the groundwater for the prior study were anaerobic and better able to take advantage of the conditions in the sample containers than the aerobic bacteria thought to initially predominate in the present study. The concentrations and trends observed in the prior study were far different (greater concentrations, for longer periods) from those seen in the present study.

It has been hypothesized that there is a correlation between turbidity and phosphorus, but no correlation between turbidity and liquid phosphorus fractions was found. 


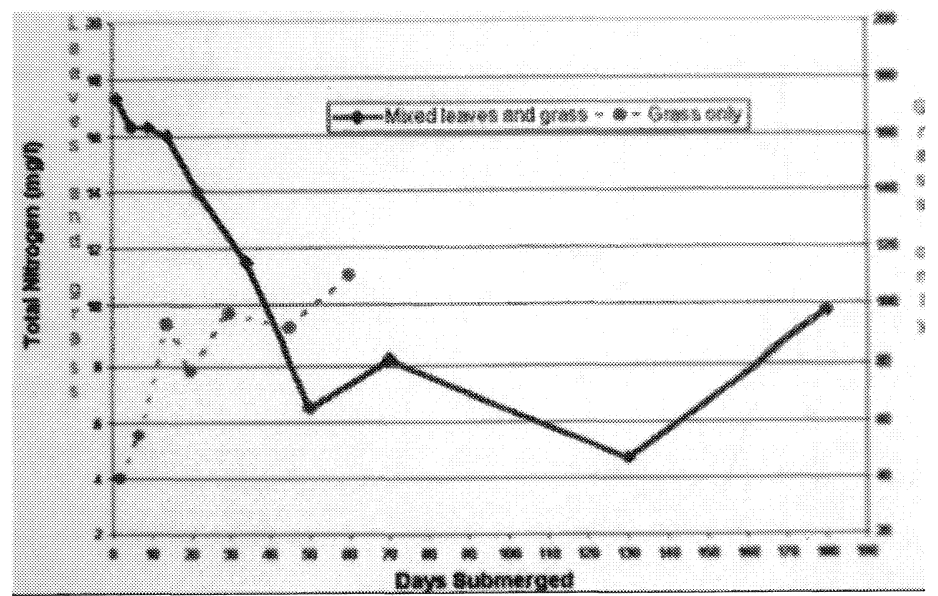

Figure 19.9 Mixed grass and leaves vs grass only, total nitrogen.

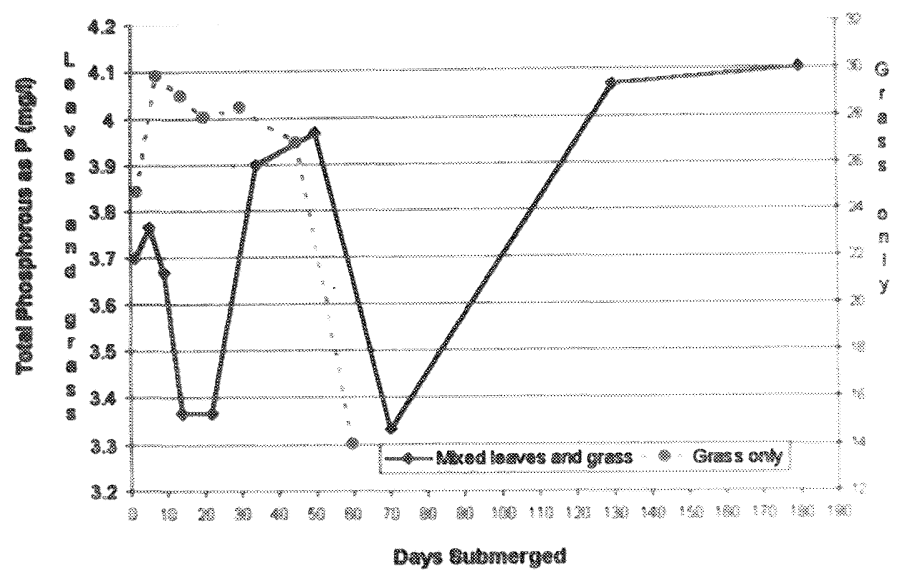

Figure 19.10 Mixed grass and leaves vs grass only, total phosphorus.

\subsection{Recommendations}

The sample volumes and weights used in the present study were selected to be representative of conditions observed in "typical" stormwater treatment BMPs. The concentrations of the "pollutant" constituents being analyzed during this study were at times very near the minimum detection limits for the contract 


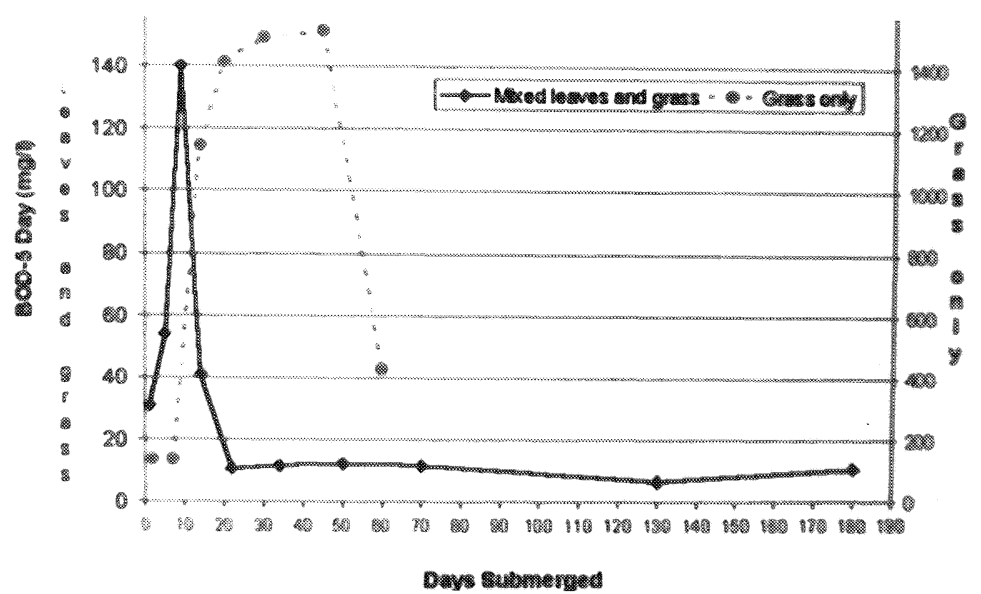

Figure 19.11 Mixed grass and leaves vs grass only, $\mathrm{BOD}_{5}$.

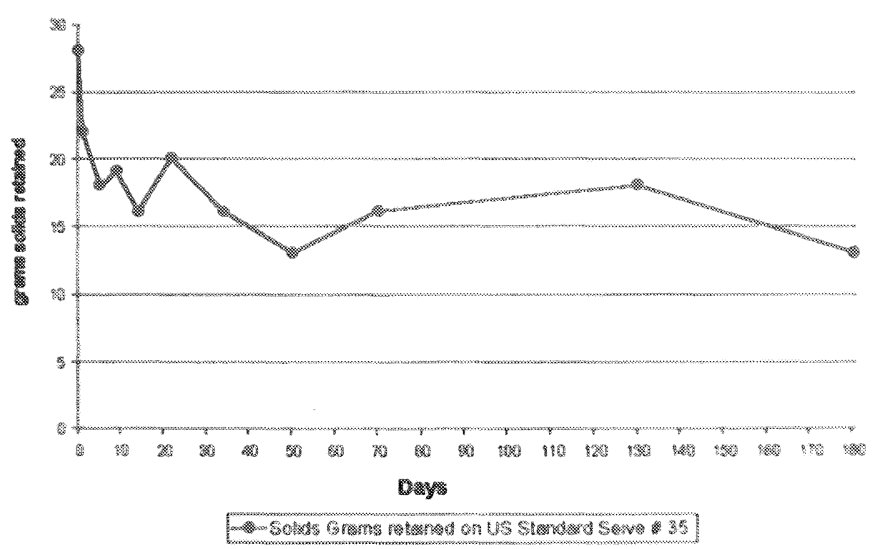

Figure 19.12 Mixed grass and leaves residual dry weight.

laboratory. As such, identification of statistically significant trends or day-point values is very difficult at the lower levels. It may be necessary to re-run this experiment with a greater volume of wet grass and leaves in order to more clearly quantify the possible contribution rates to the overlying water. Because of the great differences observed in the concentrations of the pollutants and their respective cycles between the prior and present study, it would be of value to run this study again with different grass types, or mixtures of grass and leaves. It is also recommended that grass and leaves be tested to determine how the nutrient content in dry grass and leaves changes with time. 


\section{Bibliography}

Culbert, H. and R. France. (1995) Laboratory prediction of phosphorus release from deciduous leaves to urban runoff., Water Quality Research Journal of Canada, 30(2), 243, Reference No. RP00653

Pitt, R. (1986) Runoff Controls in Wisconsin's Priority Watersheds, In 'Urban Runoff Quality-Impact and Quality Enhancement Technology: ASCE Conference Proceedings" Urbonas, B. and L. Roesner (editors), 1986 (pp. 290-313), ASCE, Reference No. BMP

D. Prasad, J.G. Henry, and R. Kovacko. (1980) Pollution Potential of Autumn Leaves in Urban Runoff., U of Kentucky Urban Hydology, Hydraulics and Sediment Control Symposia, Kentucky, pp. 197-202., Reference No. K624

Richardson, C.J., D.L. Tilton, J.A. Kadlec, J.P.M. Chamie, and W.A. Wentz. (1978) Nutrient Dynamics of Northern Wetland Ecosystems., In: R.E. Good, et al. (eds.), Freshwater Wetlands, Ecological Processes and Management Potential. Academic Press, New York, NY., Reference No. BMP

R.J. Waschbusch, W.R. Selbig, R.T. Bannerman (2000) Sources of Phosphorous in Stormwater and Street Dirt from Two Urban Residential Basins in Madison,Wisconsin,1994-95, National Conference on Tools for Urban Water Resource Management and Protection Proceedings EPA/625/R-00/001 July 2000, Chicago, IL, pp.9-31, Reference No. TUWRM002 
